\title{
DELAYED LEIDENFROST PHENOMENA ON BIOTEMPLATED NANOSTRUCTURED SURFACES
}

\author{
S. King, M. Rahman, E. Olceroglu, and M. McCarthy ${ }^{*}$
}

Drexel University, Philadelphia, Pennsylvania, USA

\section{ABSTRACT}

Using the Tobacco mosaic virus (TMV) as a nanoscale template, superhydrophilic surfaces have been fabricated and characterized showing a delay of the Leidenfrost phenomena during droplet cooling. In this work, we show that the Leidenfrost point (LFP) can be delayed by over $100^{\circ} \mathrm{C}$ with the addition of TMV nanostructures, and up to $250^{\circ} \mathrm{C}$ by using dual-scale hierarchical structures. Additionally, increases in heat transfer by nearly three orders of magnitude have been achieved as compared to flat samples at similar temperatures.

\section{INTRODUCTION}

The Leidenfrost point is the temperature at which a liquid will begin film boiling and is commonly seen when a droplet of water is placed in a hot frying pan. The droplet slides around, hovering on a cushion of vapor without wetting the surface. Eliminating this phenomenon is important in high-temperature processes where liquid-to-surface contact is critical, such as replacing nuclear reactor coolant after loss-of-coolant incidents [1]. This Late News Paper reports the first demonstration of delayed Leidenfrost effect using nanostructures that can be applied to a variety of surfaces using a simple yet powerful biotemplating technique.
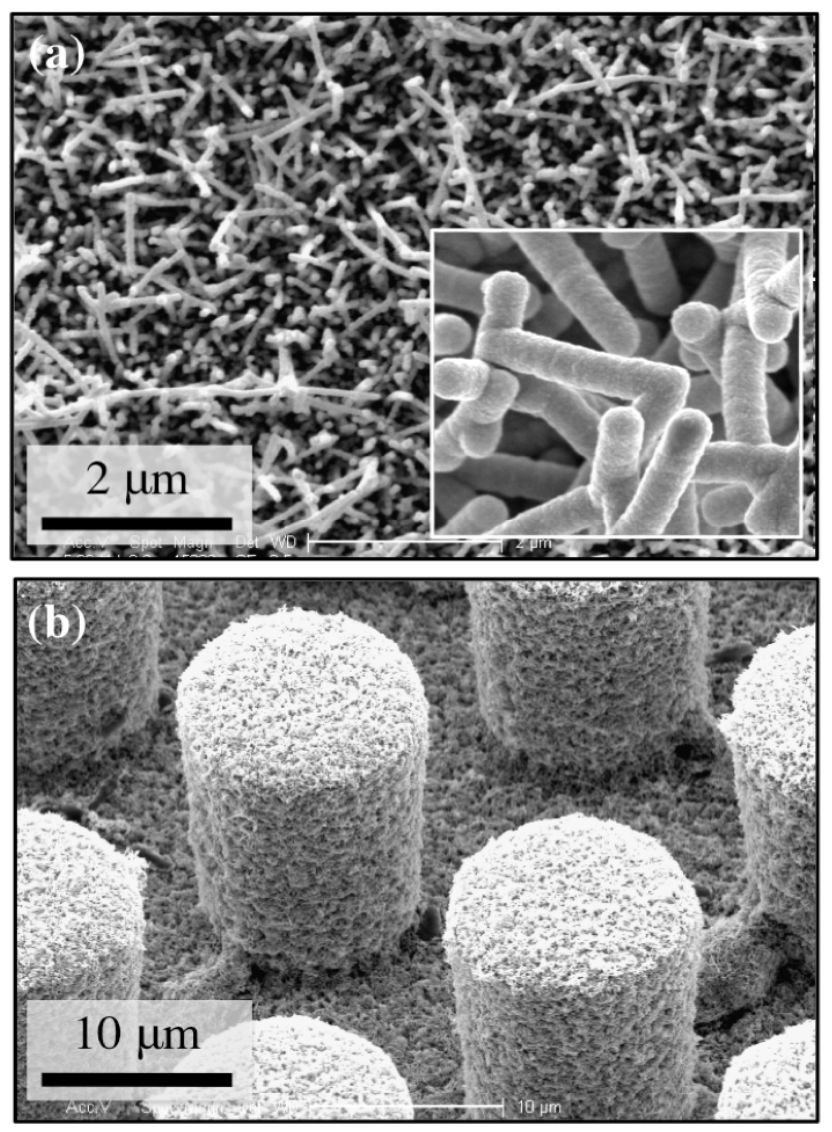

Figure 1: SEM images of (a) nickel-coated TMV nanostructures at two magnifications and (b) hierarchical structures comprised of SU-8 posts coated with TMV nanostructures.

\section{FABRICATION}

By manipulating interfaces with nanostructures, substantial increases in heat transfer can be achieved. However, traditional nanofabrication methods are difficult to integrate with real-world cooling schemes. The current work uses a simple room temperature nanofabrication process, using the self-assembly and mineralization of the TMV to create superhydrophilic surfaces for enhanced heat transfer. By sequentially submerging a surface in three room temperature solutions (TMV suspension, catalyst, and electroless nickel solution) conformal virus-templated nickel coatings are created. A similar fabrication method has been previously reported at Hilton Head 2010 and Transducers 2011 for superhydrophobic water-repellent surfaces [2] and 3D microbattery electrodes [3]. This work reports superhydrophilic surfaces for increased wetting and phase-change heat transfer. This process requires no special equipment and can be easily extended to both micro and macroscale manufacturing. Figure 1 shows SEM images of virus-templated nanostructures, and a hierarchical surface with SU-8 pillars coated with TMV. In this work, flat nickel surfaces (contact angle of $80^{\circ}$ ), TMV nanostructured surfaces $\left(<10^{\circ}\right)$, and hierarchical surfaces with post heights of $20 \mu \mathrm{m}$ and $40 \mu \mathrm{m}\left(\sim 0^{\circ}\right)$ were fabricated and tested.

\section{EXPERIMENTAL RESULTS}

The evaporation of $6 \mu \mathrm{L}$ water droplets on heated surfaces was measured using high-speed imaging to determine the LFP, the temperature corresponding to the longest evaporation time. Figure 2 shows the evaporation time versus surface temperature for each sample. As the surface temperature is increased the evaporation time decreases until the onset of film boiling, at which point the time to evaporate begins to increase for each sample. As compared to the flat sample $\left(\mathrm{LFP}=200^{\circ} \mathrm{C}\right)$, the nanostructures offset LFP by $100^{\circ} \mathrm{C}$, the $20 \mu \mathrm{m}$ hierarchical samples offset LFP by $175^{\circ} \mathrm{C}$, and the $40 \mu \mathrm{m}$ hierarchical samples offset LFP by $250^{\circ} \mathrm{C}$. We believe the posts bridge the vapor film and capillary pressure maintains the wetted surface. Figure 3 shows high-speed imaging of droplet-

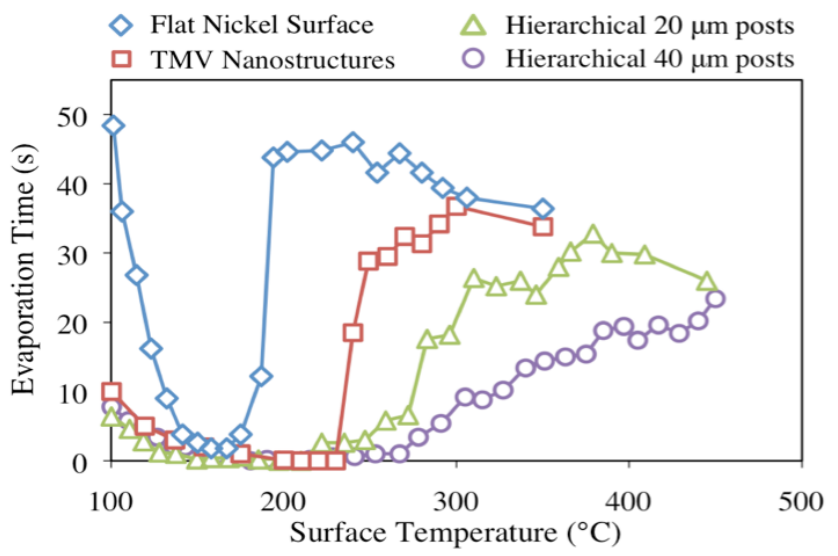

Figure 2: Experimental results of droplet evaporation time as a function of surface temperature for each sample, showing an offset in LFP with the addition of nano and microstructures. The LFP is defined as the surface temperature at the largest evaporation time. Hilton Head Island, South Carolina, June 3-7, 2012 
(a)
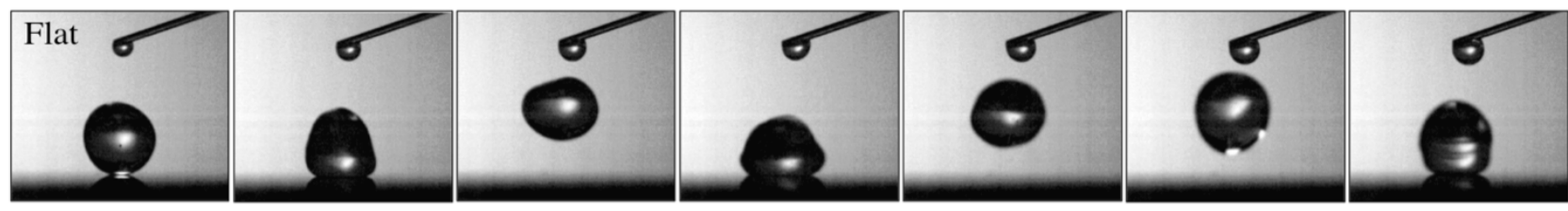

(b)
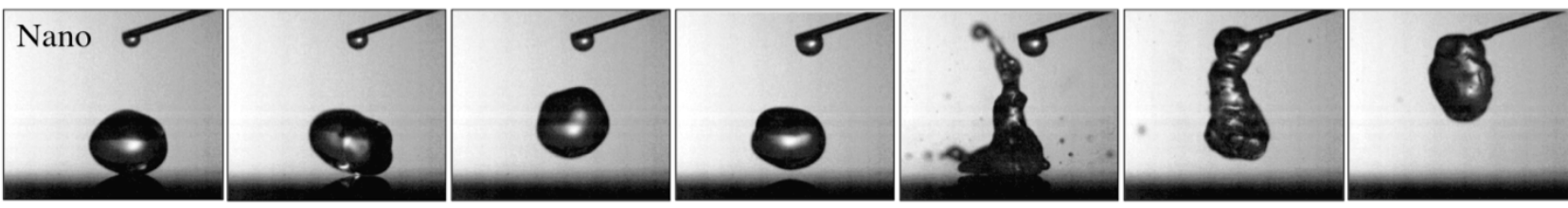

(c)

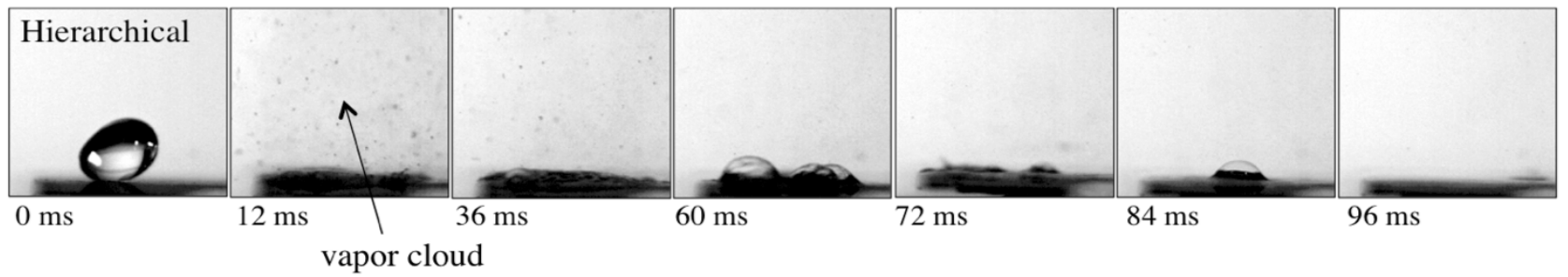

Figure 3: High-speed imaging of droplet-surface interactions at $T_{\text {Surface }}=200^{\circ} \mathrm{C}$ for (a) flat nickel surface, (b) nanostructured TMV surface, and (c) hierarchical surface with $40 \mu \mathrm{m}$ tall posts. It can be seen that the flat surface is undergoing the Leidenfrost phenomena, where the droplet does not wet the hydrophilic surface because of a thin vapor layer generated by the slow evaporation of the droplet. The nanostructured surface shows similar behavior but periodically bridges this vapor layer, leading to faster evaporation and droplet deformation. The hierarchical sample immediately wets and vaporizes the droplet quickly.

interactions at $\mathrm{T}_{\text {Surface }}=200^{\circ} \mathrm{C}$. The flat surface (Fig.3a) undergoes classical Leidenfrost behavior, bouncing on the surface and not wetting. Droplets initially bounce on the nanostructured surface (Fig. $3 \mathrm{~b}$ ), but eventually (at $\mathrm{t}=72 \mathrm{~ms}$ ) bridge the vapor layer causing a violent rupture. This process continues until the droplet has evaporated. Figure $3 \mathrm{c}$ shows the droplet immediately wetting the hierarchical sample and evaporating in under $100 \mathrm{~ms}$.

Knowing the time to evaporate a fixed volume of water, the heat transfer rate per droplet is calculated. Figure 4 shows heat transfer rates above and below the LFP for flat surfaces. It can be seen that at $\mathrm{T}_{\text {Surface }}=100^{\circ} \mathrm{C}$, the structured samples increase heat transfer by a factor of five-to-eight. At $\mathrm{T}_{\text {Surface }}=250^{\circ} \mathrm{C}$, the structured surfaces increase heat transfer by almost three orders of magnitude.

\section{CONCLUSION}

This work demonstrates the feasibility of using biotemplated nanostructures based on the TMV for delaying LFP. Offsets of $250^{\circ} \mathrm{C}$ and a nearly three order of magnitude increase in heat transfer have been demonstrated.

\section{ACKNOWLEDGEMENTS}

Travel support has been generously provided by the Transducer Research Foundation.

\section{REFERENCES}

[1] H. Kim, et al, "On the effect of surface roughness height, wettability, and nanoporosity on Leidenfrost phenomena", Appl. Phys. Lett. 98, 083121 (2011)

[2] M. McCarthy, et al, "Biomimetic Superhydrophobic Surfaces using Viral Nanotemplates for Self-Cleaning and Dropwise Condensation”, Hilton Head '10, June 6-10, Hilton Head, SC.

[3] K. Gerasopoulos, et al, "A Hierarchical Approach for the Fabrication of Three-dimensional Microbattery Electrodes," Transducers 2011, June 5-9, 2011, Beijing, China.

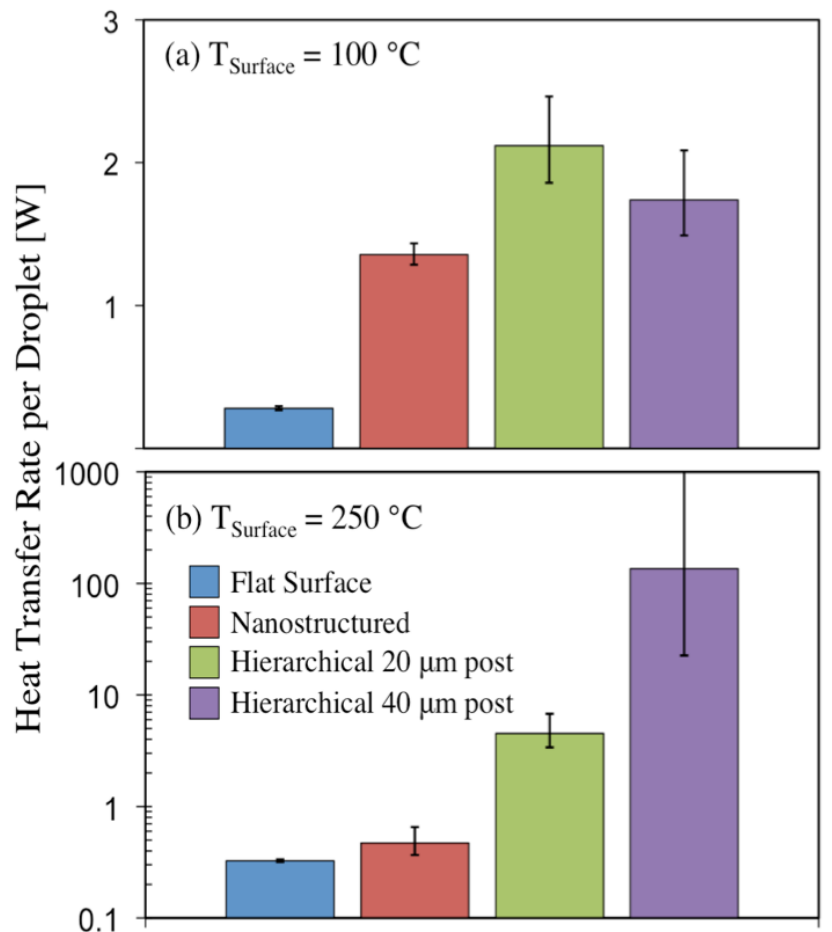

Figure 4: Heat transfer rate per droplet for each sample for (a) $T_{\text {Surface }}=100^{\circ} \mathrm{C}$ and (b) $T_{\text {Surface }}=250^{\circ} \mathrm{C}$ (on a log scale), showing substantial increases in heat transfer with nano/microstructures.

\section{CONTACT}

*Matthew McCarthy, Drexel University, 115 Randell, 3141 Chestnut St., Philadelphia, PA, 19104, mccarthy@coe.drexel.edu, 215-895-2841. 